\section{LAZER TERAPÊUTICO: PESQUISA-AÇÃO COM TRABALHADORES DE SERVIÇOS DE SAÚDE MENTAL, ÁLCOOL E OUTRAS DROGAS}

\author{
THERAPEUTIC LEISURE: ACTION RESEARCH WITH HEALTHCARE \\ WORKERS FROM MENTAL HEALTH SERVICES FOR USERS OF \\ ALCOHOL AND OTHER DRUGS
}

OCIO TERAPÉUTICO: INVESTIGACIÓN-ACCIÓN CON TRABAJADORES DE SERVICIOS DE SALUD MENTAL, ALCOHOL Y OTRAS DROGAS

\author{
Heitor Martins Pasquim*, Celia Maria Sivalli Campos**, \\ Cassia Baldini Soares**
}

\begin{abstract}
Palavras chave: Atividades de Lazer.

Educação em saúde.

Centros de

Tratamento

de Abuso de

Substâncias.

Saúde Mental.

Resumo: Objetivo: Compreender as representações cotidianas de trabalhadores da saúde mental sobre lazer, drogas e educação. Método: pesquisa-ação emancipatória, desenvolvida em dez oficinas, com 11 participantes de serviços de saúde mental. A análise baseou-se na teoria das representações cotidianas. Resultados: A mentalidade dominante, relativa a consumidores de drogas e à educação nessa área, mostrou-se conservadora e proibicionista. O lazer terapêutico tradicionalmente usado nos serviços foi representado criticamente como método de controle dos usuários. Conclusões: Sugere-se a adoção de oficinas educativas de lazer de caráter emancipatório em serviços de saúde mental, álcool e outras drogas.
\end{abstract}

Keywords:

Leisure activities.

Health education.

Treatment centers

for substance

abuse.

Mental Health.

Palabras clave: Actividades Recreativas. Educación en Salud.

Centros de

Tratamiento de Abuso de Sustancias. Salud Mental

Abstract: Goal: To understand everyday representations of mental health workers about leisure, drugs and education. Method: emancipatory action-research study developed in ten workshops with 11 participants from mental health services. The analysis was based on the theory of everyday representations. Results: The dominant mentality regarding drug users and drug education was linked to a conservative and prohibitionist perspective. The therapeutic leisure traditionally used in health services was critically represented as a method for controlling users. Conclusions: Adoption of emancipatory leisure workshops is recommended in alcohol and other drugs services.
Resumen: Objetivo: Comprender las representaciones cotidianas de trabajadores de la salud mental sobre ocio, drogas y educación. Método: investigación-acción emancipadora, desarrollada en diez talleres, con 11 participantes de servicios de salud mental. El análisis estuvo basado en la teoría de las representaciones cotidianas. Resultados: la mentalidad dominante con respecto a los consumidores de drogas y a la educación en el área se mostró conservadora y prohibicionista. El ocio terapéutico, tradicionalmente utilizado en los servicios, fue representado críticamente como un método de control de los usuarios. Conclusiones: se sugiere la adopción de talleres educativos de ocio de carácter emancipador en los servicios de salud mental, alcohol y otras drogas.

* Universidade Federal de Goiás. Goiânia, GO, Brasil. E-mail:

hpasquim@gmail.com

** Universidade de São Paulo, São Paulo, SP, Brasil.

E-mail:

sivallicelia@gmail.com; cassiaso@usp.br

Recebido em: 05-02-2019 Aprovado em: 16-11-2019 Publicado em: 11-02-2020 (c) (1) (8) Licence 


\section{INTRODUÇÃO}

Atividades de lazer fazem parte da lista de ações desenvolvidas como forma de tratamento em serviços de saúde mental, incluindo-se os serviços que prestam cuidados a pessoas que fazem uso de drogas, lícitas ou ilícitas (BRASIL, 2003). A comunidade científica frequentemente defende que essas atividades devem ser um componente na prevenção e tratamento do uso de drogas (MORE et al., 2017).

No entanto, não há consenso quanto a sua abordagem, há estudos que sinalizam até mesmo resultados conflitantes (UNODC, 2018). Pinheiro, Andrade e Micheli (2016) verificaram correlação entre determinadas atividades físicas de lazer e maior uso de drogas, enquanto Nasser e outros (2016) encontraram relação positiva entre o baixo uso de drogas e atividades físicas de lazer. Isso mostra a relevância de estudos que venham a tematizar o consumo de drogas e as chamadas atividades de lazer.

Para entender essas atividades é necessário compreender o fenômeno lazer. O lazer, conforme a sociologia do trabalho, não é sinônimo de atividade recreativa (GOMES, 2004), podendo ser conceituado, a partir da perspectiva marxista, como fenômeno originário das tensões entre capital e trabalho (MASCARENHAS, 2005). Do ponto de vista dialético, pode-se dizer que, como síntese de contrários, o lazer não se resume à submissão ao capital, mas encerra possibilidades emancipatórias por meio de reflexões sobre a produção social e a cultura.

Essa desnaturalização do lazer permite rever concepções ingênuas ou idealizadas (MASCARENHAS, 2014), que tentam camuflar a relação do fenômeno com a totalidade social, invocando o conceito de lazer como tempo livre para o desfrute da cultura. Esse processo de desnaturalização permite ainda compreender potencialidades nas estratégias e projetos voltados para aumentar, diminuir ou preencher o tempo disponível (MARCELLINO, 2014).

Apesar dessas potencialidades, percebe-se que as atividades educativas e de lazer que envolvem a temática das drogas estão majoritariamente fundamentadas no proibicionismo (SOARES, 2007; PASQUIM; LACHTIM e SOARES, 2019), com discursos e projetos autoritários e estigmatizantes, que generalizam informações não-científicas sobre drogas e consumidores de drogas, o que molda estereótipos e caricaturas, em reforço à ideologia que ampara o sistema droga, conforme conceito descrito por Baratta (1994). O sistema droga é socialmente dominante e se fundamenta em perspectiva funcionalista, que sugere um ciclo sem saída, restando ao sujeito perseverar na sua abstinência e ao Estado legitimar a perseguição cruel aos pobres, envolvidos no ambiente deletério do narcotráfico, e subvencionar tratamentos ineficientes e retrógrados. Essa perspectiva de ação despreza a análise crítica que explica o consumo como consequência da produção e distribuição de drogas e como consequência das dinâmicas capitalistas contemporâneas (SOARES, 2007).

Com a finalidade de agregar elementos empíricos aos estudos do cuidado em saúde mental, em especial na área de drogas, esta pesquisa foi desenvolvida objetivando compreender as representações cotidianas sobre lazer, consumo de drogas e educação sobre drogas expressas por trabalhadores de serviços de saúde mental. 


\section{MÉTODO}

As representações cotidianas de trabalhadores de saúde mental foram identificadas por meio de pesquisa qualitativa realizada em São Paulo, Brasil, nos moldes da pesquisa-ação emancipatória (CORDEIRO; SOARES, 2016), valendo-se de oficinas educativas (ALMEIDA; TRAPÉ; SOARES, 2013; SOARES, et al., 2009), que foram gravadas e posteriormente transcritas, para captar o fluxo de diálogos, interações e reações dos participantes. Neste caso, as unidades de análise foram identificadas a partir de um processo educativo com sucessivas aproximações que tomaram a forma de unidades representacionais.

Utilizou-se, para essa análise, a teoria das representações cotidianas. As representações cotidianas constituem a diversidade de manifestações do conhecimento e da cultura populares. Para essa teoria, as representações cotidianas expressam a consciência sobre aspectos da realidade (VIANA, 2015).

A análise das representações cotidianas envolve captar e compreender unidades representacionais que expressam a consciência contraditória e em transformação. Neste caso, transformações da consciência coletiva que aconteceram durante o processo educativo que atravessa as oficinas. Importa retomar que se pretende acessar as convicções, consciência enraizado, e não só as opiniões, que são passageiras e voláteis (LACHTIM; PASQUIM; SOARES, 2015). Essa convicção ou consciência enraizada pode ser identificada por narrativa estruturada, repetição em diferentes encontros e/ ou consciência coletiva que orienta a prática.

Em etapa preliminar à apreensão das convicções, a pesquisa foi apresentada em todos os Centro de Atenção Psicossocial Álcool e outras Drogas - CAPS AD das regiões Centro (2 CAPS AD) e Sudeste (8 CAPS AD) da cidade de São Paulo, quando os interessados na temática foram convidados a participar do estudo. Ressalta-se que os contatos obtidos no processo de aprovação e de apresentação da pesquisa foram essenciais para alcançar individualmente trabalhadores interessados em outras regiões de São Paulo.

Os participantes da pesquisa-ação eram trabalhadores da saúde mental em serviços públicos especializados no cuidado de consumidores de drogas, sendo que o contato aconteceu a partir da liberação dos serviços e da interação já existente com a universidade. O critério de seleção dos sujeitos foi intencional, isto é, participaram os que se identificaram com e aceitaram fazer parte, após apresentação da pesquisa nos CAPS AD.

Participaram da pesquisa 11 trabalhadores da saúde - professores de educação física (5), psicólogos (3), redutores de danos (2), assistente social (1) - que chamaremos de pesquisadores internos, conforme expressão descrita por Soares, Cordeiro, Campos e Oliveira (2018).

Para a teoria das representações cotidianas, é necessário identificar a posição dos indivíduos na sociedade para entender a constituição da consciência. Tais informações foram levantadas durante as oficinas e serão apresentadas no Quadro 1. 
Quadro 1 - Perfil dos trabalhadores da saúde.

\begin{tabular}{|c|c|c|}
\hline Participante & $\begin{array}{l}\text { Informações } \\
\text { sociodemográficas }\end{array}$ & Formação e trajetória profissional \\
\hline T1 & $\begin{array}{l}\text { Homem; } \\
37 \text { anos; } \\
\text { Solteiro; } \\
\text { Servidor público estadual; } \\
\text { Trabalha e estuda. }\end{array}$ & $\begin{array}{l}\text { Professor de Educação Física. } \\
\text { Cursou o SUPERA (Sistema para detecção do Uso abusivo e dependência de substâncias Psicoativas: } \\
\text { Encaminhamento, intervenção breve, Reinserção social e Acompanhamento). Mestre em Ciências e } \\
\text { doutorando. Trabalhou em diferentes academias, em NASF e em um Centro de Atenção Integrado à Saúde } \\
\text { Mental. }\end{array}$ \\
\hline $\mathrm{T} 2$ & $\begin{array}{l}\text { Homem; } \\
25 \text { anos; } \\
\text { Solteiro; } \\
\text { Regime celetista e temporário; } \\
\text { Trabalha e estuda. }\end{array}$ & $\begin{array}{l}\text { Redutor de danos. } \\
\text { Estudou em escola técnica estadual; Especialista em Responsabilidade Social Empresarial e } \\
\text { Sustentabilidade; Graduando em Direito. } \\
\text { Trabalhou como oficineiro em CAPS adulto e como redutor de danos em CAPS AD. }\end{array}$ \\
\hline T3 & $\begin{array}{l}\text { Mulher; } \\
52 \text { anos; } \\
\text { Tem filho; } \\
\text { Regime celetista e autônoma. }\end{array}$ & $\begin{array}{l}\text { Professora de Educação Física. } \\
\text { Trabalhou em Escolas estaduais e particulares; Clubes (Técnica de natação); Academias; Hospital } \\
\text { psiquiátrico até 2015; personal trainer; e CAPS AD. }\end{array}$ \\
\hline T5 & $\begin{array}{l}\text { Homem; } \\
34 \text { anos; } \\
\text { Casado; } \\
\text { Regime celetista e autônomo. }\end{array}$ & $\begin{array}{l}\text { Professor de Educação Física. } \\
\text { Pós-Graduado em Saúde Mental e Atenção Psicossocial; Pós-Graduado em Atividade Física Adaptada e } \\
\text { Saúde. } \\
\text { Trabalhou em CAPS Adulto, em caráter temporário ( } 2015 \text { - 2016); Cuidador de Jovem com Transtorno do } \\
\text { Espectro do Autismo (2012 - 2015); Academia como professor de Musculação (2012); Centro de Referência } \\
\text { da Criança e do Adolescente Butantã e Pinheiros (CRECA) como educador social (2005 - 2008); CAPS AD; e } \\
\text { personal trainer. }\end{array}$ \\
\hline T6 & $\begin{array}{l}\text { Mulher; } \\
26 \text { anos; } \\
\text { Casada; } \\
\text { Regime celetista. }\end{array}$ & $\begin{array}{l}\text { Assistente social. } \\
\text { Atuou como cuidadora em Unidade de Acolhimento e agente de saúde em CAPS até } 2015 \text { e como assistente } \\
\text { social em CAPS AD. }\end{array}$ \\
\hline
\end{tabular}

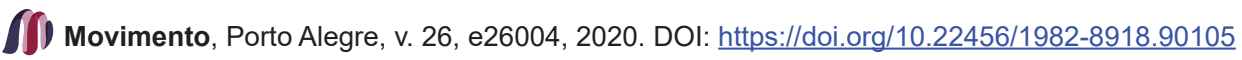


Continuação do quadro 1

\begin{tabular}{|c|c|c|}
\hline T7 & $\begin{array}{l}\text { Mulher; } \\
32 \text { anos; } \\
\text { Casada; } \\
\text { Plantonista } 12 \times 36 \text {. }\end{array}$ & $\begin{array}{l}\text { Redutora de danos. } \\
\text { Estudou em escola pública. } \\
\text { Trabalhou como consultora (trabalho administrativo em coleta de exames). Em } 2012 \text { começou a trabalhar } \\
\text { como redutora de danos em uma residência terapêutica (Unidade de Acolhimento) ligada ao CAPS adulto e } \\
\text { CAPS AD. }\end{array}$ \\
\hline T8 & $\begin{array}{l}\text { Mulher; } \\
33 \text { anos; } \\
\text { Trabalha e estuda; } \\
\text { Regime celetista; } \\
\text { Casada. }\end{array}$ & $\begin{array}{l}\text { Psicóloga. } \\
\text { Formação em Tecnóloga, Gestão em RH. } \\
\text { Começou a trabalhar com } 16 \text { anos: Trabalhou como caixa de supermercado; atendente de lanchonete; } \\
\text { operadora de telemarketing; recepcionista; estagiária em recursos humanos; analista de recursos humanos; } \\
\text { agente redutora de danos (CAPS AD); e psicóloga (CAPS Adulto). }\end{array}$ \\
\hline T9 & $\begin{array}{l}\text { Mulher; } \\
25 \text { anos; } \\
\text { Estuda e estagia; } \\
\text { Bolsa de estágio. }\end{array}$ & $\begin{array}{l}\text { Psicóloga. } \\
\text { Escola pública. Iniciou na área de logística como separadora de mercadoria, passando para o controle de } \\
\text { qualidade e depois finalizando em conferente. }\end{array}$ \\
\hline T10 & $\begin{array}{l}\text { Mulher; } \\
31 \text { anos; } \\
\text { Regime celetista e funcionária } \\
\text { pública; } \\
\text { Casada. }\end{array}$ & $\begin{array}{l}\text { Professora de Educação Física. } \\
\text { Pós-graduada em Psicomotricidade. } \\
\text { Trabalhou em CAPS Infantil (2009-2010); CAPS AD (2010-2014); e CAISM e CAPS adulto (desde 2014). }\end{array}$ \\
\hline T11 & $\begin{array}{l}\text { Mulher; } \\
29 \text { anos } \\
\text { União estável com proprietário } \\
\text { de rede de empresas; } \\
\text { Regime celetista e autônoma. }\end{array}$ & $\begin{array}{l}\text { Professora de Educação Física. } \\
\text { Intercâmbio em Portugal; Programa de Aprimoramento Profissional, 2014; Especialização em Dependência } \\
\text { Química 2015; Trabalha no Programa Recomeço desde } 2014 \text { e como personal trainer (autônoma). }\end{array}$ \\
\hline
\end{tabular}

Fonte: elaboração própria.

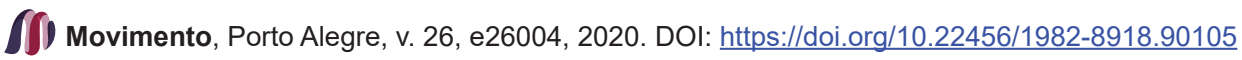


A diferença de experiência profissional entre os participantes era notável. Um dos participantes tinha apenas 24 dias de experiência na área, outro tinha quase uma década de trabalho com a questão das drogas, sendo que a maioria era recémformada e tinha poucos anos de experiência profissional. O grupo foi composto por trabalhadores assalariados, com jornada dupla, isto é, com mais de um emprego ou emprego e estudo. A maioria estava submetida ao regime celetista em Organização Social de Saúde (OSS). Quase todos os participantes estavam casados e tinham completado o terceiro grau, o que Ihes conferiam condições de vida estáveis.

As oficinas foram coordenadas pelo pesquisador responsável T1 e por convidados, especialistas no tema abordado - que chamaremos de pesquisadores externos. Ocorreram dez oficinas de aproximadamente três horas cada. As oficinas foram realizadas na Escola de Enfermagem da Universidade de São Paulo, no primeiro semestre de 2017.

Essas oficinas foram tomadas como técnica de coleta de dados. Para Soares et al. (2009) e Cordeiro, Soares e Campos (2013), as oficinas educativas orientadas pela Pesquisa-Ação Emancipatória (PAE) permitem que as representações cotidianas venham à tona, porque o processo de instrumentalização dos trabalhadores acontece por meio de processo pedagógico participativo.

A PAE possui quatro critérios, a saber: participação; processo realizado em ciclos de espiral; produção de conhecimento; e transformação de práticas (CORDEIRO, 2016). A pesquisa ação-emancipatória não é qualquer tipo de reflexão sobre a ação, senão uma forma de investigação-ação, que, atendendo aos critérios comuns a outros tipos de pesquisa acadêmica (TRIPP, 2005), informa à ação que se decide tomar para transformar a práxis social (CORDEIRO, 2016).

Cordeiro (2016) aponta que a PAE tem como meta explícita mudar o status quo, assinalando a necessidade e a possibilidade de transformação social, uma vez que o conhecimento é produzido de forma a submeter à reflexão os problemas apresentados na realidade concreta.

A metodologia da oficina educativa em perspectiva emancipatória (SOARES et al., 2018a) possibilita que a cada encontro as reflexões e discussões sobre o tema proposto sejam incorporadas às reflexões e sínteses dos encontros anteriores, produzindo novas sínteses. Portanto, a avaliação das necessidades teórico-práticas do grupo orientou a condução das oficinas. Ela aconteceu de forma contínua. Isto é, conforme as avaliações iam sendo construídas, novas reflexões sobre a prática em saúde e novas temáticas eram abordadas.

Os temas abordados nas oficinas foram: estigma sobre usuários de drogas; característica da sociabilidade, das relações sociais capitalistas; trabalho e lazer na contemporaneidade; perspectivas metodológicas e teóricas da saúde coletiva; atividades de lazer em serviços de saúde; educação sobre drogas; necessidades sociais de saúde; território; objeto e finalidade das práticas em saúde.

A síntese crítica construída pelo grupo de pesquisa "Fortalecimento e Desgaste no Trabalho e na Vida: bases para a intervenção em saúde coletiva", a partir das discussões e estudos anteriores, foi utilizada como marco inicial para a condução das oficinas educativas (SOARES et al., 2018b). Citam-se o arcabouço teórico metodológico das experiências de instrumentalização de Agentes Comunitários da Saúde, realizada por Cordeiro, Soares e Campos (2013), instrumentalização de 
jovens escolares, realizada por Oliveira, Soares e Silva (2016) e instrumentalização de trabalhadores de instituições sociais (SOARES et al., 2009).

A pesquisa foi aprovada pelo Comitê de Ética em Pesquisa da Escola de Enfermagem da Universidade de São Paulo - EEUSP, pelo Comitê de Ética em Pesquisa da Prefeitura de São Paulo e permitida pelas Coordenadorias Regionais de Saúde Sudeste e Centro da cidade de São Paulo.

\section{RESULTADOS E DISCUSSÃO}

Para contextualizar a exposição dos resultados, as representações cotidianas serão apresentadas, sempre que possível, juntamente com as estratégias correspondentes utilizadas nas oficinas. As representações cotidianas analisadas serão destacadas nos Quadros 2, 3 e 4 para facilitar identificação e análise.

A análise das representações exige captar transformações representacionais em movimento dialético. Neste artigo, optou-se por não recortar excertos das falas individuais, a fim de evidenciar as convicções coletivas.

As conviç̧ões não serão subdivididas para diferenciar representações por categoria profissional. Embora haja especificidades no trabalho em saúde em função de instrumentos diversos das profissões, o trabalhador coletivo, que coopera para compor o cuidado em saúde, compartilha objetos de trabalho e concepções sobre o objeto (ALMEIDA; TRAPÉ; SOARES, 2013). No caso do cuidado ao usuário de drogas é também a clínica que hegemonicamente fundamenta o processo de intervenção e delimita o "doente de drogas" como objeto do trabalho. As representações cotidianas nesse sentido são comuns ao trabalhador coletivo em saúde e perpassam o cotidiano de todos os trabalhadores.

\subsection{LAZER}

Quadro 2 - Representações cotidianas sobre o lazer.

\begin{tabular}{l}
\hline As atividades de lazer são atividades compensatórias \\
\hline Comportamentos desajustados podem ser substituídos por um "lazer saudável" \\
\hline $\begin{array}{l}\text { O "lazer terapêutico" faz parte das estratégias de captação e de controle de usuários em serviços } \\
\text { de saúde }\end{array}$
\end{tabular}

Fonte: elaboração própria.

Com a intenção de iniciar um processo de desnaturalização do lazer, o pesquisador proponente pediu ao grupo que compartilhasse como desfrutavam o lazer no cotidiano. Tocar violão, tomar um longo banho, ouvir música relaxante, beber cerveja foram atividades lembradas, em oposição as obrigações cotidianas do trabalho e da vida, que lhes causava desgastes e esgotamento. Estas, por sua vez, foram associadas à dinâmica do trabalho que, entre outros desgastes, produz competição entre trabalhadores e a necessidade de buscar cursos e certificados o que, acrescido às atividades do trabalho, produz um ritmo de vida extenuante. Nesse contexto, o fenômeno lazer foi frequentemente associado a um tempo de alívio e de fuga da rotina. Portanto, compensatório. 
De fato, o lazer não é uma atividade completamente desinteressada nem é um tempo totalmente livre. O capitalismo gera o mal-estar social e as opções de alívio, submetendo ambos ao mercado (VIANA, 2014). No capitalismo, o lazer tem tanto as funções de alívio quanto de escape do trabalho alienado (CUSTODIO; SOUSA; MASCARENHAS; HÚNGARO, 2009), seja no shopping (PADILHA, 2008) ou na Cracolândia (ARRUDA; SOARES; TRAPÉ; CORDEIRO, 2017).

Ao serem estimulados a identificar, como exercício problematizador, atividades de lazer autênticas e alienadas, ponderaram que não existe uma atividade plenamente autêntica ou apenas alienada. Entretanto, para o grupo, o atual processo de mercantilização privilegia práticas alienadas, incluindo-se o consumo de drogas lícitas ou ilícitas, que tem as características de qualquer outra mercadoria. Refletiram ainda que a liberdade de escolha do lazer é apenas a aparência do fenômeno.

Outra representação cotidiana que se destacou durante as oficinas foi a de que atividades de lazer substituem o desejo de consumir drogas, especificamente aquelas atividades desenvolvidas no cotidiano de tratamento nos serviços de saúde. Os pesquisadores internos as compararam com atividades que visavam, em essência, corrigir os comportamentos dos usuários considerados desajustados e socialmente inadequados. Vale assinalar que os mesmos trabalhadores que relataram anteriormente o consumo de drogas como uma atividade legítima (beber cerveja) para compensar os desgastes do trabalho e da vida, sinalizaram, no âmbito do trabalho, que as atividades de lazer voltadas para usuários de drogas evitariam o "caminho das drogas".

Os trabalhadores acenaram com o desenvolvimento de grande variedade de opções saudáveis de lazer como solução ideal para ocupar o tempo e ajudar os sujeitos em tratamento a buscar prazer sem o uso de drogas. Esta intenção substitutiva denuncia uma perspectiva de análise funcionalista do lazer, especialmente aquele que sistematicamente combate o uso de drogas.

Com o decorrer dos encontros, a catarse coletiva produzida pela reflexão em grupo construiu uma nova síntese que reconheceu que, mesmo que algumas formas estejam geralmente relacionadas a danos maiores, o consumo de drogas não é, por si só, um desvio de comportamento, mas resposta a necessidades humanas. Síntese que vai ao encontro de estudos do professor Henrique Carneiro (2002), que descreve que as drogas são historicamente parte dos ritos humanos.

Quando foi proposto ao grupo identificar objetivos fundamentais para as práticas de saúde, evidenciou-se a representação cotidiana que caracterizou as atividades nos serviços de saúde mental como atividades terapêuticas. Nesse sentido, as atividades de lazer com finalidade preventiva foram descritas como "lazer terapêutico".

Advogaram que esse lazer terapêutico amenizaria a monotonia dos serviços, ao mesmo tempo em que atrairia os usuários, facilitando o envolvimento emocional. Os trabalhadores da saúde mental consideraram também que o lazer terapêutico poderia por vezes ser utilizado como recompensa ou privilégio para usuários que participam de atividades consideradas nobres, por exemplo, consultas individuais e "grupos verbais". Relataram também que a reflexão sobre a fruição do lazer e o direito ao lazer, não acontecem.

Um dos trabalhadores lembrou-se de um usuário de drogas que foi desligado do tratamento porque se interessava por jogar futebol no CAPS, mas se recusava 
a participar das atividades qualificadas como sérias pelo serviço. Portanto, nesse serviço a atividade futebol era institucionalizada como recompensa pelo cumprimento de alguma obrigação; e, por isso, pode ser caracterizada como funcionalista.

Essa mentalidade está associada a conceitos e valores dominantes, baseados no controle social. Seu oposto é a mentalidade associada à emancipação humana, construída a partir de concepções e valores antiproibicionistas, porque humanitários e igualitários (PASQUIM; SOARES, 2015).

A mentalidade dominante pode ser observada nos casos em que o lazer assume a função de matriz disciplinar para usuários de drogas. Essa perspectiva funcionalista ignora o direito social ao lazer (BACHELADENSKI; MATIELLO, 2010) e a potencialidade da educação por meio dele (FERNANDES; HÚNGARO; ATHAYDE, 2011).

$\mathrm{Na}$ medida que os encontros se sucederam, os pesquisados internos identificaram que a monotonia no cotidiano dos serviços de saúde é um problema relacionado à institucionalização das atividades e não atributo do comportamento dos usuários destes serviços. Perceberam que o "lazer terapêutico" consiste em uma ferramenta institucional de controle e tratamento moral.

Finalmente, os participantes concluíram que seria importante elaborar estratégias que associassem a produção social de cultura à educação em saúde. Dessa forma, os pilares fundamentais do modo dominante de pensamento sobre a liberdade e o tempo livre poderiam ser compreendidos, especialmente a mercantilização, a competição social e a burocratização da vida das pessoas.

Além disso, os participantes da pesquisa sugeriram duas propostas educativas. A primeira seria para promover reflexões sobre o lazer entre consumidores de drogas e o direito constitucional ao lazer. A segunda seria para estimular a fruição de práticas autogeridas, criativas e autênticas entre os usuários do serviço de saúde.

\subsection{CONSUMO DE DROGAS}

Quadro 3 - Representações cotidianas sobre o consumo de drogas.

\begin{tabular}{|l|}
\hline O consumo de droga é uma escolha individual \\
\hline O dependente químico não tem força de vontade \\
\hline Grupos marginalizados são alvos de diagnósticos e de ações autoritárias na área de drogas \\
\hline
\end{tabular}

Fonte: elaboração própria.

Os pesquisadores internos foram estimulados a refletir sobre o que gostariam de abolir no trabalho, na sociedade e na política. Durante esta discussão, foi expressa reiteradamente a representação cotidiana que afirma que o consumo de drogas é uma escolha individual.

De fato, existe tendência à opinião pública sugerir que os indivíduos são os únicos responsáveis pelo uso de drogas, o que manifesta posição liberal, sinalizando, como afirmam Santos e Soares (2013), ideologia que posiciona o uso de drogas como algo independente da dinâmica social, que idealiza o consumo de drogas como um fenômeno isolado do modo de produzir e de existir em sociedade. 
Os trabalhadores da saúde mental expuseram durante o processo das oficinas a identificação do usuário de drogas com sentimentos de fraqueza e de falta de força de vontade e, ao mesmo tempo, a droga com características de vilã, de inimiga. Desta forma, como analisaram Santos e Soares (2013), a droga passa a ser primordialmente uma mercadoria fetichizada, reproduzindo com isto a ideologia que cria o sujeito-consumidor coisificado e a droga humanizada.

Para destacar esse fetiche, como um importante fenômeno do processo de produção social do problema da mercadoria droga, foi utilizado nas oficinas educativas, junto com outros autores da saúde coletiva (OLIVEIRA; SOARES; BATISTA, 2016; PASQUIM; SOARES, 2015), o termo "consumidor de drogas".

Se a droga é valorizada como mercadoria de alívio pessoal que responde ao mal-estar na atualidade, o cuidado deve estar integrado à busca consciente de respostas coletivas para as necessidades sociais de saúde. Advoga-se aqui um processo de desalienação, embora a perspectiva liberal vigente propague valores associados à individualidade, tanto no alcance de metas quanto na resolução de problemas e aquisição de respostas a pressões sociais, desconsiderando que as possibilidades de constituição de respostas são adquiridas nas relações estabelecidas socialmente.

Outra estratégia desenvolvida no processo das oficinas foi a discussão em grupo do texto jornalístico Mental illness is a result of misery, yet still we stigmatise it, de Richard Bentall, publicado no The Guardian (2016). A discussão produziu a expressão da representação cotidiana que afirma que grupos marginalizados são alvos de diagnósticos e ações autoritárias. Tal representação vai ao encontro dos fatos relatados pelo coletivo.

A discussão deste texto revelou o estigma presente na retórica da saúde contra pacientes psiquiátricos, estigma esse relacionado à afirmação de que eles sofrem por conta de seus supostos defeitos no cérebro. No caso específico dos usuários de drogas, o problema estaria delimitado ao sistema de recompensas do cérebro. Relatou-se uma forte presença dessa retórica no cotidiano dos serviços.

Essa retórica é questionável precisamente porque atribui à droga um poder absoluto e unilateral. Para Fraser et al. (2017) essa abordagem omite a possibilidade de análise da realidade dos sujeitos, contribuindo com isso para o processo de estigmatização social das pessoas envolvidas com drogas.

Não admira que os termos "viciado em drogas" (VELHO, 1999) e "doentes mentais" (AMARANTE; TORRE, 2010) sejam utilizados como expressões pejorativas ou categorias de acusação. Eles servem para invalidar a humanidade presente em cada pessoa e em suas atitudes.

A ideia da escalada iminente entre consumo e dependência de drogas foi contestada pelo grupo de pesquisadores internos. Na realidade dos serviços, os dependentes eram a exceção e não a regra. Portanto, é possível afirmar que o julgamento que atribui ao consumo de drogas a inevitabilidade do uso abusivo e, consequentemente, a um caminho sem retorno em direção à dependência, expressa uma representação simplificada e ilusória da realidade. Para Hart (2017), esse tipo de ideia limita a potencialidade dos trabalhadores que cuidam de pessoas que fazem uso de drogas lícitas ou ilícitas. 
Os trabalhadores reunidos nas oficinas disseram ainda que os problemas associados às drogas apresentam em geral um sofrimento crônico amplamente relacionado ao abandono social e à insegurança. Mencionaram os bolivianos como exemplo de grupo social marginalizado, que são comumente alvos da retórica da saúde no cotidiano da cidade de São Paulo. Essas pessoas enfrentam enormes barreiras para acessar serviços de saúde pública, de educação e de cultura.

A opinião dos participantes da pesquisa foi de que a epidemia nesses grupos marginalizados não é de transtornos mentais, mas de diagnósticos. Todavia, essa opinião não parece mobilizar ações cotidianas para além de práticas compensatórias e individuais.

O grupo citou as intervenções autoritárias da saúde pública e da justiça, como o encarceramento e a internação compulsória em massa, como dispositivo vago e genérico, que equivale a uma "caçada" de indivíduos diagnosticados como dependentes de drogas. De fato, Sidarta Ribeiro e Luís Fernando Tófoli (2018) advogam que pregar abstinência para todos é ineficaz e irrealista.

Nesse sentido, urge compreender as raízes do processo saúde-doençacuidado, o que propiciaria o reconhecimento das origens dos desentendimentos e frustrações que surgem a partir da reprodução de práticas de trabalho que reiteram o tratamento tradicional dispensado aos usuários de drogas, centrado na finalidade da abstinência, imposta pelos serviços, geralmente causadora de insucessos durante e após o tratamento.

As críticas sobre as explicações farmacológicas e psiquiátricas para o consumo de drogas estão alinhadas com a perspectiva da saúde coletiva (PASQUIM; SOARES, 2016; SOARES; CAMPOS; LEITE; SOUZA, 2009; ARRUDA et al., 2017; PASQUIM; SOARES, 2015; SANTOS; SOARES, 2013) e encontram afinidades com resultados de estudos de outras áreas do conhecimento (HART, 2017; LEVINE; SIEGEL, 2015; HEIM, 2014; FRASER, 2017).

\subsection{EDUCAÇÃO SOBRE DROGAS}

Quadro 4 - Representações cotidianas sobre a educação sobre drogas.

\begin{tabular}{|l|}
\hline A falta de informações sobre os riscos explicaria a experimentação e o abuso em drogas \\
\hline Na área de drogas, a educação hegemônica parte de uma abordagem terrorista \\
\hline O objetivo da educação sobre drogas deve ser sempre prevenir o consumo \\
\hline
\end{tabular}

Fonte: elaboração própria

Quando se discutiram os materiais de apoio à educação sobre drogas, foi exposta a representação que afirmou que a falta de informações sobre riscos explica a experimentação de drogas. Naquele momento, parte do grupo expressou o entendimento de que no geral a sociedade é permissiva em relação às drogas e por isto é difícil as pessoas dizerem não a elas. Todavia, após assistirem o documentário Crack, é possível entender, os pesquisadores internos criticaram a abordagem hegemônica da educação sobre drogas e observaram que a realidade da mercadoria droga, produção-distribuição-consumo na sociedade capitalista, está ausente do processo educativo. 
Relataram que na experiência deles os programas de educação sobre drogas utilizam apenas estratégias de transferência de informações negativas, com foco nas drogas ilícitas e avaliaram como inúteis os programas educativos que utilizam estratégias amedrontadoras, como se elas fossem suficientes para afastar os jovens das drogas. Ao contrário, o que conseguem é afastar os jovens da possibilidade de buscar os trabalhadores de saúde para dirimir dúvidas relacionadas ao uso das substâncias, ou mesmo para buscar ajuda.

O paradigma do risco é, na maioria dos casos, utilizado por trabalhadores que compartilham a visão proibicionista (CARDOSO; PAIXÃO; SOARES; COELHO, 2013). Todavia, o contexto da saúde mental é muito complexo para ser abordado por práticas simplificadoras pautadas no proibicionismo e no objetivo de correção de disfuncionalidades.

Segundo Pasquim e Soares (2015), o paradigma do risco presente nas políticas públicas sobre drogas propõe uma compreensão multifatorial. Para essa compreensão o desequilíbrio, em qualquer dos fatores, geraria o abuso ou no mínimo o risco de recaída. Neste caso, o lazer é tomado como um fator de proteção. No lugar da noção do risco, a Saúde Coletiva toma a determinação social da saúde para a qual o risco não é apenas um modelo interpretativo, senão uma matriz disciplinar (BREILH, 2015) que submete a realidade a modelos idealistas.

A epidemiologia do risco e o tratamento focado na abstinência ou ainda o foco na redução do uso de substâncias estabelece limites para a compreensão do problema e atribui ao usuário de drogas a falsa identidade de ser uma pessoa desordenada (FOMIATTI; MOORE; FRASER, 2017). Além disso, a oposição binária entre o uso de drogas e o autocuidado é questionável. Moore, Pienaar, Dilkes-Frayne e Fraser (2017) demonstraram que a biografia dos consumidores de drogas pode incluir cuidados à própria saúde. Conforme Cordeiro, Godoy e Soares (2014), é possível mobilizar a perspectiva da redução de danos como alternativa às práticas em saúde que buscam exclusivamente à abstinência.

Considerar que a educação na área de drogas deve sempre prevenir o consumo de drogas pode ser caracterizada como uma convicção ilusória (SANTOS; SOARES; CAMPOS, 2010). É uma convicção porque foi expressa em diferentes oficinas e parece estar enraizada nas práticas cotidianas do grupo. É ilusória porque desde tempos imemoráveis é impossível evitar o encontro das pessoas com drogas. Ademais, nem todo usuário delas fará uso prejudicial para a saúde.

Em um dos últimos encontros do grupo, foi apresentada a oficina em saúde mental como instrumento privilegiado de educação em saúde (KINKER; IMBRIZI, 2015) e que compõe com outras estratégias com finalidade terapêutica. A oficina pode assumir perspectiva emancipatória, quando promove práticas criativas e promove a análise crítica de práticas reiterativas (SOARES et al., 2018a; GODOY-VIEIRA et al., 2018).

A partir de então, o grupo reconheceu que essa estratégia com centralidade educativa poderia integrar conteúdos do lazer. Nesse caso, oficinas de lazer poderiam estar alinhadas à redução de danos por meio da educação radicalmente participativa, orientada pelo encadeamento de estratégias que mobilizem produções, reflexões e discussões sobre o tema. 
Nesse caso, a oficina de lazer seria uma experiência pedagógica que tem o potencial para problematizar o lazer entre consumidores de drogas na atualidade. Como experiência pedagógica, ela difere da ocupação de tempo e deve apresentar processos cíclicos de planejamento, desenvolvimento e avaliação.

\subsection{ANÁLISE GLOBAL DAS OFICINAS}

As oficinas mapearam as representações ideológicas sobre o uso de drogas e também apontaram a urgência de construir um arcabouço teórico metodológico para uma proposta crítica as atividades de lazer tradicionais desenvolvidas em serviços voltados ao cuidado a usuários de drogas.

Há muitas visões e interesses antagônicos entre os sujeitos que buscam responder ao problema droga (PASSOS; SOUZA, 2011; SOUZA; CARVALHO, 2015). Enfatiza-se, a partir desse estudo, a necessidade de superar o lazer terapêutico e a atividade de lazer como fator de proteção descontextualizada. Para tanto, propomos oficinas educativas de lazer como um método provocador e privilegiado de educação sobre drogas em serviços de saúde mental. Todavia, mais estudos são necessários para desenvolver estratégias coerentes com o potencial educativo de atividades que produzam cultura e que problematizem o lazer também em contextos externos aos dos serviços de saúde mental.

Além disso, evidentemente, uma luta política, dentro e fora dos serviços de saúde mental, também é parte fundamental na transformação das práticas de saúde na sociedade.

\section{CONCLUSÕES}

Esta pesquisa-ação permitiu compreender e incitar transformações no cuidado a usuários de drogas. Os participantes elaboraram análises críticas e indicaram a urgência em superar intervenções conservadoras e controladoras. As mudanças durante o processo se mostraram qualitativamente relevantes. Convicções que não mudaram completamente durante o processo da pesquisa-ação revelam um tipo de ideia que reitera o consumo de drogas associado a desvio.

Foi relatado que a mentalidade predominante sobre usuários de drogas e educação em drogas tem sido associada a perspectivas conservadoras e proibicionistas. Além disso, atividades de lazer nos CAPS AD foram descritas como método de controle de usuários.

Sugere-se a adoção de oficinas educativas de lazer, orientadas por perspectiva emancipatória, para integrar o cuidado em saúde e a redução de danos, possibilitando a reflexão e a criação de produções orientadas para a crítica da sociedade, a fim de superar a perspectiva preventivista e proibicionista.

Nesse sentido, indicam-se duas propostas para as oficinas educativas de lazer em serviços de saúde mental, álcool e outras drogas. A primeira é promover reflexões sobre o lazer entre consumidores de drogas e o direito ao lazer. A segunda é estimular a fruição de práticas autogeridas, criativas e autênticas entre os usuários do serviço de saúde.

A oficina de lazer é uma experiência pedagógica que tem o potencial para problematizar o lazer entre consumidores de drogas na atualidade. Como experiência 
pedagógica, ela difere da ocupação de tempo e deve apresentar processos cíclicos de planejamento, desenvolvimento e avaliação.

\section{REFERÊNCIAS}

ALMEIDA, AH; TRAPÉ, Carla Andrea; SOARES, Cassia Baldini. Educação em saúde no trabalho de enfermagem. In: SOARES Cassia Baldini, CAMPOS Celia Maria Sivalli (eds). Fundamentos de saúde coletiva e o cuidado de enfermagem. São Paulo: Manole, 2013. p. 293-322.

AMARANTE, Paulo; TORRE, Eduardo Henrique Guimarães. Medicalização e determinação social dos transtornos mentais: a questão da indústria de medicamentos na produção de saber e políticas. In: NOGUEIRA, Roberto Passos. Determinação social da saúde e reforma sanitária. Rio de Janeiro: Cebes, 2010. p. 151-160.

ARRUDA, Marcel Segalla Bueno; SOARES, Cassia Baldini; TRAPÉ, Carla Andrea; CORDEIRO, Luciana. Crackland: Beyond Crack Cocaine. Social Medicine, v. 11, n. 1, p. 8-17, jan. 2017.

BACHELADENSKI, Miguel Sidenei; MATIELLO JUNIOR, Edgard. Contributions from the critical leisure field to the health promotion. Ciência Saúde Coletiva, v. 15, n. 5, p. 25692579, ago. 2010.

BARATTA, Alessandro. Introdução a uma sociologia da droga. In: MESQUITA, Fabio; BASTOS, Francisco Inácio; organizadores. Drogas e Aids: estratégias de redução de danos. São Paulo: Hucitec; 1994. p. 21-44.

BENTALL, Richard. Mental illness is a result of misery, yet still we stigmatise it. The Guardian, 26 fev. 2016. Disponível em: https://www.theguardian.com/commentisfree/2016/ feb/26/mental-illness-misery-childhood-traumas. Acesso em: 02 out. 2019.

BRASIL. Ministério da Saúde. Política do Ministério da Saúde para a Atenção Integral a Usuários de Álcool e Outras Drogas. Brasília, 2003.

BREILH, Jaime. Epidemiologia crítica: ciência emancipadora e interculturalidade. 1. ed. $1^{\text {a }}$ reimpressão. Rio de Janeiro: Fiocruz, 2015.

CARDOSO, Bianca Silva; PAIXÃO, lara Ribeiro; SOARES, Cassia Baldini; COELHO, Heloisa Veiga. Educational materials on drugs: a qualitative analysis. Saúde \&

Transformação Social, v. 4, n. 2, p. 149-156, 2013.

CARNEIRO, Henrique. As necessidades humanas e o proibicionismo das drogas no século XX. Revista Outubro, v. 6, n. 2, p. 115-128, 2002.

CORDEIRO, Luciana. Pesquisa-ação na área da saúde: uma proposta marxista a partir de revisão de escopo. 211 f. Tese (Doutorado). São Paulo: Escola de Enfermagem da Universidade de São Paulo, São Paulo, 2016.

CORDEIRO, Luciana; GODOY-VIEIRA, Aline; SOARES, Cassia Baldini. A supervisão como processo educativo: Construindo o paradigma de redução de danos emancipatória com uma equipe de CAPS-AD. Cadernos de Terapia Ocupacional da UFSCar, v. 22, n. 1SE, p. 153159, 2014. 
CORDEIRO, Luciana; SOARES, Cassia Baldini. Implementation of evidence-based health care using action research: an emancipatory approach. International Journal of Nursing Practice, v. 22, n. 4, p. 333-338, ago. 2016.

CORDEIRO, Luciana; SOARES, Cassia Baldini; CAMPOS, Celia Maria Sivalli. Pesquisa ação na perspectiva da Saúde Coletiva: relato de experiência da formação de agentes comunitários da saúde para o enfrentamento do consumo prejudicial de drogas. Saúde \& Transformação Social. Florianópolis (SC), v. 4, n. 2, p. 106-116, 2013.

CUSTODIO, Mariana Lopes; SOUSA, Wilson Luiz Lino; MASCARENHAS, Fernando; HÚNGARO, Edson Marcelo. Leisure and the kingdom of freedom: reflections from the ontology of social being. Licere, v. 12, n. 4, p. 1-21, 2009.

FERNANDES, Erick Rodrigo; HUNGARO, Edson Marcelo; ATHAYDE, Pedro Fernando. Lazer, trabalho e sociedade: notas introdutórias sobre o lazer como um direito social, Buenos Aires, Argentina. EFDeportes.com, Revista Digital, v. 16, n. 155, abr. 2011. Disponível em: https://www.efdeportes.com/efd155/o-lazer-como-um-direito-social.htm. Acesso em: 03 dez. 2018.

FOMIATTI, Renae; MOORE, David John; FRASER, Suzanne. Interpellating recovery: The politics of 'identity' in recovery-focused treatment. International Journal of Drug Policy, v. 44, p. 174-182, jun. 2017.

FRASER, Suzanne. The future of 'addiction': Critique and composition. International Journal of Drug Policy, v. 44, p. 130-134, jun. 2017.

FRASER, Suzanne; PIENAAR, Kiran; DILKES-FRAYNE, Ella; MOORE, David John; KOKANOVIC, Renata; TRELOAR, Carla; DUNLOP, Adrian. Addiction stigma and the biopolitics of liberal modernity: A qualitative analysis. International Journal of Drug Policy, v. 44, p. 192-201, jun. 2017.

GODOY-VIEIRA, Aline; SOARES, Cassia Baldini; CORDEIRO, Luciana; CAMPOS, Celia Maria Sivalli. Inclusive and emancipatory approaches to occupational therapy practice in substance-use contexts. Canadian Journal of Occupational Therapy, v. 85, n. 4, p. 307317, 2018.

GOMES, Christianne Luce. Lazer - Concepções. In: GOMES, Christianne Luce (Org.). Dicionário Crítico do Lazer. Belo Horizonte: Autêntica, 2004. p. 119-126.

HART, Carl L. Viewing addiction as a brain disease promotes social Injustice. Nature Human Behavior, v. 1, n. 3, 0055, fev. 2017.

HEIM, Derek. Addiction: not just brain malfunction. Nature, v. 507, n. 40, p.5, 2014.

KINKER, Fernando Sfair; IMBRIZI, Jaquelina Maria. Myth of the Therapeutic Workshops.

Revista Polis e Psique, v. 5, n. 3, p. 61-79, dez. 2015.

LACHTIM, Sheila Aparecida Ferreira; PASQUIM, Heitor Martins; SOARES, Cassia Baldini. Representações Cotidianas: Proposta de Superação da Análise de Conteúdo a partir da Dialética Marxista. Sociologia em Rede, v. 5, n. 5, p. 3-11, 2015.

LEVINE, Harry G.; SIEGEL, Loren. Marijuana Madness: The Scandal of New York City's Racist Marijuana Possession Arrests. In: ETERNO, John A. (Ed). The New York City Police Department: The Impact of Its Policies and Practices. New York: CRC Press, 2015. p. 117-161.

MARCELLINO, Nelson Carvalho. Lazer e educação. 17. ed. Campinas: Papirus, 2014. 
MASCARENHAS, Fernando. Entre o ócio e o negócio: teses acerca da anatomia do lazer. 308 f. Tese (Doutorado) - Faculdade de Educação Física, UNICAMP, Campinas, 2005.

MASCARENHAS, Fernando. Tempo Livre. In: GONZÁLEZ, Fernando Jaime;

FENSTERSEIFER, Paulo Evaldo (Org.). Dicionário crítico de Educação Física. 3. ed. ljuí: UNIJUÍ, 2014. p. 637-640.

MOORE, David John; PIENAAR, Kiran; DILKES-FRAYNE, Ella; FRASER Suzanne. Challenging the addiction/ health binary with assemblage thinking: a qualitative analysis. International Journal of Drug Policy, v. 44, p. 155-163, jun. 2017.

MORE, Alissa; JACKSON, Ben; DIMMOCK, James A.; THORNTON, Ashleigh L.; COLTHART, Allan; FURZER, Bonnie J. Exercise in the Treatment of Youth Substance Use Disorders: Review and Recommendations. Front Psychol, v. 8, p. 1839, out. 2017.

NASSER, Roberta Lacerda; BRANCO, Jeronimo Costa; RIZZATO, Diogo Lara; VECCHIO, Fabrício Boscolo; WIENER, Carolina; MESQUITA, Paula; SOUZA, Luciano Dias de Mattos; SILVA, Ricardo Azevedo; JANSEN, Karen. Leisure-time physical activity and licit substance use in a population sample of young adults. Ciência \& Saúde Coletiva, v. 21, n. 1, p. 63-70, jan. 2016.

OLIVEIRA, Elda; SOARES, Cassia Baldini; BATISTA, Leandro Leonardo. Representações cotidianas de jovens sobre a periferia. Revista Brasileira de Enfermagem, v. 69, n. 6, p.1147-1153, dez. 2016.

OLIVEIRA, Elda; SOARES, Cassia Baldini; SILVA, Julia de Almeida. Pesquisa-ação emancipatória com jovens escolares: relato de experiência. Revista Gaúcha de Enfermagem, v. 37, n. 3, p. 1-6, dez. 2016.

PADILHA, Valquíria. Desafios da crítica imanente do lazer e do consumo a partir do shopping center. ArtCultura, v. 10, n. 17, p. 103-119, 2008.

PASQUIM, Heitor Martins; SOARES, Cassia Baldini. Leisure, collective health and drug consumption. Licere, v. 18, n. 2, p. 305-328, jun. 2015.

PASQUIM, Heitor Martins; SOARES, Cassia Baldini; SANTORO, Ricardo. Drug education games for youth. Social Medicine, v. 10, n. 2, p. 61-69, ago. 2016.

PASQUIM, Heitor Martins; LACHTIM, Sheila Aparecida Ferreira; SOARES, Cassia Baldini. Conteúdo sobre drogas em jogos para dispositivos móveis. Revista da Escola de Enfermagem da USP, v. 53, e03520, out. 2019.

PASSOS, Eduardo Henrique; SOUZA, Tadeu Paula. Redução de danos e saúde pública: construções alternativas à política global de 'guerra às drogas'. Psicologia e Sociedade, v. 23, n. 1, p. 154-162, jan./abr. 2011.

PINHEIRO, Bruno de Oliveira; ANDRADE, André Luiz Monezi; MICHELI, Denise. Relationship between levels of physical activity and quality of life in drug use in teenagers. Revista Eletrônica Saúde Mental Álcool e Drogas, v. 12, n. 3, p. 178-87, set. 2016.

RIBEIRO, Sidarta; TÓFOLI, Luís Fernando. Não é o uso de drogas que configura um problema social. PODER360, 01 fev. 2018. Disponível em: https://www.poder360.com.br/ opiniao/governo/nao-e-o-uso-de-drogas-que-configura-um-problema-social-diz-sidartaribeirol. Acesso em: 02 out. 2019.

SANTOS, Vilmar Ezequiel; SOARES, Cassia Baldini. Psychoactive substance abuse from a collective health perspective: a reflection about social values and fetishism. Saúde \& Transformação Social, v. 4, n. 2, p. 38-54, 2013. 
SANTOS, Vilmar Ezequiel; SOARES, Cassia Baldini; CAMPOS, Celia Maria Sivalli. Harm reduction: analysis of the concepts that guide practices in Brazil. Physis Revista de Saúde Coletiva, v. 20, n. 3, p. 995-1015, 2010.

SOARES, Cassia Baldini. Consumo contemporâneo de drogas e juventude: a construção do objeto na perspectiva da saúde coletiva. 195 f. Tese (Livre-docência) - Escola de Enfermagem da USP, São Paulo, 2007.

SOARES, CB; CAMPOS, Celia Maria Sivalli; LEITE, Adriana de Souza; SOUZA, Cristina Lourdes Leite. Young people and drug consumption: workshops to provide tools for workers in social institutions, from a collective health perspective. Interface (Botucatu), v. 13, n. 28, p. 189-199, mar. 2009.

SOARES, Cassia Baldini; CAMPOS, Celia Maria Sivalli; SOUZA, Helton Saragor; GODOYVIEIRA, Aline; CORDEIRO, Luciana; LOPES, lara de Oliveira; CAVALCANTI, Beatriz Souza Garofalo. Oficinas emancipatórias como intervenção em saúde do(a) trabalhador(a). Revista Brasileira de Saúde Ocupacional, v. 43, supl. 1, e7s, 2018a.

SOARES, Cassia Baldini; CORDEIRO, Luciana; CAMPOS, Celia Maria Sivalli; OLIVEIRA, LC. Pesquisa-Ação Emancipatória: metodologia coerente com o materialismo histórico e dialético. In: TOLEDO, Renata Ferraz; ROSA, Teresa Etsuko da Costa; KEINERT, Tania Mezzomo; CORTIZO, Carlos Tato (org.). Pesquisa Participativa em Saúde: vertentes e veredas. Temas em Saúde Coletiva (24). São Paulo: Editora do Instituto de Saúde, 2018b. p. 153-165.

SOUZA, Tadeu de Paula; CARVALHO, Sérgio R. Reduzindo danos e ampliando a clínica: desafios para a garantia do acesso universal e os confrontos com a internação compulsória. In: BRASIL. Ministério da Saúde. Cadernos HumanizaSUS: Brasília-DF: Ministério da Saúde, 2015. v. 5, p. 215-232. (Saúde Mental).

TRIPP, David. Pesquisa-ação: uma introdução metodológica. Educação e Pesquisa, v. 31, n. 3, p. 443-466, dez. 2005.

UNODC - UNITED NATIONS OFFICE ON DRUGS AND CRIME. International Standards On Drug Use Prevention: Second Updated Edition. Disponível em: https://www.unodc. org/documents/prevention/standards_180412.pdf. Acesso em 03 dez 2018.

VELHO, Gilberto. Duas categorias de acusação na cultura brasileira contemporânea. In: VELHO Gilberto (Ed). Individualismo e cultura. Rio de Janeiro: Zahar, 1999. p. 55-64.

VIANA, Nildo. A mercantilização do lazer. Revista Espaço Livre, v. 9, n. 18, p. 56-68, jul./ dez. 2014.

VIANA, Nildo. A Pesquisa em Representações Cotidianas. Lisboa: Chiado, 2015. 